DIGITALCOMMONS @WAYNESTATE-
Michigan Journal of Counseling: Research, Theory and Practice

$10-5-2018$

\title{
Multilingualism in Counselor Education and Human Services Professionals: Implications for a New Training Paradigm
}

\author{
Roberto Swazo \\ University of Northern lowa, roberto.swazo@uni.edu \\ Dorota Celinska \\ Roosevelt University
}

Follow this and additional works at: https://digitalcommons.wayne.edu/mijoc

Part of the Counselor Education Commons, and the Linguistics Commons

\section{Recommended Citation}

Swazo, R. \& Celinska, D. (2018). Multilingualism in Counselor Education and Human Services Professionals: Implications for a New Training Paradigm. Michigan Journal of Counseling: Theory, Research, and Practice, 43(1), eP1090 (Prepublication). doi: 10.22237/mijoc/1533600000

This Article is brought to you for free and open access by the Open Access Journals at DigitalCommons@WayneState. It has been accepted for inclusion in Michigan Journal of Counseling: Research, Theory and Practice by an authorized editor of DigitalCommons@WayneState. 
Multilingualism in Counselor Education and Human Services Professionals:

Implications for a New Training Paradigm

\section{Cover Page Footnote}

Preprint, Online: October 5, 2018; Revised: March 22, 2021 
DOI: $10.22237 / \mathrm{mijoc} / 1533600000$

eP1090, Online: October 5, 2018; Revised: March 22, 2021

\title{
Multilingualism in Counselor Education and Human Services Professionals: Implications for a New Training Paradigm
}

Roberto Swazo
University of
Northern Iowa

\author{
Dorota Celinska \\ Roosevelt University
}

\begin{abstract}
This study analyzes the relationships among the three distinct levels of language and cultural-linguistic professional competences. A total of 483 participants from three U.S. and one Central American university representing the fields of counseling, social work, family services, and psychology were surveyed. The results suggest that there is a large multilingual training deficit among human service providers in the U.S. Training programs need to make curricular revisions to include bi/multilingual training consistent with multilingual clientele. Recommendations for culturally-embedded and non-native language use are provided to increase cultural-linguistic competences among counselor education trainees.
\end{abstract}

Keywords: multilingual competence, monolingualism, cultural-linguistic competence

Roberto Swazo, School of Applied Human Sciences, University of Northern Iowa; Dorota Celinska, College of Education, Roosevelt University.

Correspondence concerning this article should be addressed to Roberto Swazo, School of Applied Human Sciences, University of Northern Iowa, Cedar Falls, IA, 50614. E-mail: roberto.swazo@uni.edu

Visit the Michigan Journal of Counseling online: https://digitalcommons.wayne.edu/mijoc/

Article license: Creative Commons Attribution 4.0 International 


\section{Multilingualism in Counselor Education and Human \\ Services Professionals: Implications for a New \\ Training Paradigm}

For decades, multiculturalism has been an essential component of professional training in the areas of counselor education, psychology, and the human services professions (Arredondo, Tovar-Blank, \& Parham, 2008; Pedersen, 1988; Sue, Arredondo \& McDavis, 1992). For example, adhering to the Multicultural Counseling Competencies (MCC) (Sue \& Sue, 1999), national multicultural standards for counseling program accreditation have been established to ensure an integration of multicultural principles into the curricula (American Psychological Association, 2002; Council for Accreditation of Counseling and Related Educational Programs, 2009; 2016). In keeping with the objective of developing multiculturally competent counselors, psychologists, and human services providers, a variety of multicultural conceptual models and training programs have been generated through the last decades (Celinska \& Swazo, 2015; Marbley, Steele, \& McAuliffe, 2011; Swazo \& Celinska, 2014; Vázquez \& García-Vázquez, 2003).

Regardless of the conceptual model, the landscape of multicultural training and competence has been traditionally dominated by issues of ethnic, racial, gender and sexual identities (Arredondo, Tovar-Blank, \& Parham, 2008; Buckley \& Foldy, 2010; Sue, Arredondo \& McDavis, 1992; Sue \& Sue, 1999). In contrast, the element of multilingual competence has been utterly non-existent in the multicultural training models and programs (Hurley, Gerstein, \& Egisdóttir, 2013; Peters, Sawyer \& Guzman, 2014). Yet, the appropriate use of language in counseling and psychological practices constitutes the primary tool for rendering an accurate diagnosis, establishment of goals, and a treatment plan (Shoeman, Chiliza, Emsley, \& Southwood, 2008; Swazo, 2013).

\section{The Importance of Multilingual Competence for Human Services Professionals}

The importance of multilingual competences in counseling, human services, and therapeutic professional practice stems from the fact that language is not always translatable, especially when describing emotions and critical details (Kokaliari, Catanzarite, \& Berzoff, 2013). For example, the use of adjectives, adverbs, and specific feeling words is anchored in very specific contextual and cultural experiences that are not simply translated into a second language. Additionally, non-native speakers of English may be at a disadvantage to fully 
articulate their cognitions, emotions, behaviors, and to accurately recall critical life events using their second language (Shoeman, et al., 2008).

The influence of language use in professional practices is well illustrated in a single subject study of psychological services provided to a South African individual who spoke Afrikaans as his native language and was also fluent in English (Shoeman, et al., 2008). Initially, the interviewer used English to communicate during the intake interview and evaluation process. It was reported that whenever the South African individual used English he would speak calmly, coherently, and would utilize brief descriptive annotations when prompted. However, as soon as he was impelled to use Afrikaans instead of English, he would become animated, articulated, and able to use a more extensive vocabulary. Consequently, the language transition lead the interviewer to more complex potential diagnoses and deeper understanding of the client's previous hallucinations and delusions since the client displayed a broader array of traits and symptoms in his native language.

The positive impact of the counselor's multilingual competence on the comfort level of the bilingual clients and their positive regard for the counselor is evident in the results of a study by Ramos-Sanchez (2009) who interviewed 65 bilingual Mexican-American college students who received services at a college counseling center. Among the four counselors involved, two were MexicanAmerican and two were White/Euro American. One counselor of each ethnic background conducted the counseling sessions in English while the other counselor conducted the sessions equally using English and Spanish. The results indicated that White/Euro American counselor who possessed strong second language skills was perceived by the bilingual clients as more culturally competent than the monolingual White/Euro American counterpart.

Consistently with the clients' positive experiences with multilingual counselors, 101 monolingual and multilingual therapists of 20 different nationalities surveyed by Costa and Dewaele (2014) reported the importance of multilingual counseling as a vehicle for strengthening the counselor-client connection. In addition, the majority of the surveyed counselors linked the use of multiple languages in their practice to enhanced critical thinking of their own use of language. In particular, multilingual counselors facilitated the effectiveness of therapy by simplifying the use of their native language while conveying messages to the bilingual clients. According to Espín (2013), therapy is completely relational and language is a crucial part of all human relationships. Ivers, Ivers, and Duffey (2013) suggested that "learning another person's language demonstrates competence, respect, and interest" (p. 230), which can lead to 
"empowerment of non-English-speaking clients" (p. 227) and improved clientclinician relations.

\section{Multilingual Context for Human Services Professionals}

The lack of multilingual competence within multicultural training programs is of particular concern in light of the increasing levels of multilingualism and multiculturalism in the U.S. as a nation of immigrants. For instance, when the original Multicultural Competencies and Standards were developed, there was no mention of updating the current curriculum in the area of multilingualism (Sue, Arredondo, McDavis, 1992). Likewise, there was an absence of plurilingualism and specificity of training in the updated version entitled: "Exploring the Different Levels of Multicultural Counseling Training in Counselor Education" (D’Andrea \& Daniels, 2011). Most recently, a survey conducted with 57 Council for Accreditation of Counseling and Related Educational Programs (CACREP) doctoral programs, showed the extent to which multicultural issues were addressed in coursework, practicum, and scholarship activities. Also, the study investigated the level in which faculty members participate in multicultural professional development, teaching, supervision, and research. The results and conclusions did not include one single recommendation or need in the area of multilingualism (Brooks, Kim, Moye, Oglesby, \& Hargett, 2015). Then, historically, since the inception of the Multicultural Competencies and Standards twenty five years ago, the area of multilingualism has not been properly addressed in research studies and as result, not considered for potential curricular changes.

Understanding the pressing need to have properly trained counselors in the field, several institutions are providing bilingual certificates in addition to the standard curriculum (i.e., Hunter College, NYU-Steinhardt, University of La Verne). However, the Council of Accredited Counseling and Related Educational Programs (CACREP) and the American Psychological Association (APA) do not require as part of the multicultural curricular standards the inclusion of bilingual or multilingual courses.

In contrast with these curricular deficiencies, and according to the Center for Immigration Studies (2016), 21\% of the population in the U.S. speaks other language at home other than English. Although many of those are bilingual, more than 25 million residents say they speak English at levels they would rate as less than "very well" (U.S. Census Bureau, 2015). Indeed, more than 39 million residents spoke Spanish at home last year - a jump of more than 11 million compared with 14 years earlier. Chinese was the second most prominent language 
at home, with 3.1 million residents speaking it - up from 2 million in 2000. Just as startling is the growth of foreign languages among school-age children. In California, 43.9 percent of children eligible for primary or secondary school speak language other than English at home. In Texas, the figure is 36.2 percent, and in Nevada, it's 32.9 percent. These figures are conservative in nature, and it is estimated that a larger number of individuals speak English as a second language at home. Importantly, this percentage is projected to increase rapidly in the upcoming decades (Shin \& Kominski, 2010). Consistent with this projection is the continuous and substantial growth of non-English speakers in the K-12 school system, leading to the expansion of English as a Second Language, bilingual, and language immersion programs (U.S. Department of Education, 2015). The influx of non-native English speakers in the U.S. school system has been paralleled by the number of non-native English speaking adults joining the workforce. As an illustration, between 2016 and 2035, the majority of the growth experienced in the working-age population will be as a result of immigration (National Association of Manufacturers, 2006).

The diverse language foliage of the U.S. population presents a challenge for counselors, psychologists, and human services professionals who do not possess multicultural and/or multilingual competencies to address the needs of the increasingly linguistically diverse clientele. For example, Atkins' (2007) survey of 8,000 counselors in California indicated that only 5\% rated themselves as multilingual while 95\% indicated that they were monolingual English speakers. The lack of consideration of multilingual competence in professional preparation is further exemplified in the results of a survey of psychology doctoral students (Hurley, Gerstein, \& Egisdóttir, 2013). Among 83 doctoral students who represented 32 of the 63 American Psychological Association (APA) accredited counseling psychology programs in the nation, none were required to take a foreign language class. In another study conducted by Rosenblum (2011), the results indicated that bilingualism and multilingualism have not been afforded adequate exploration in clinical social work practice. This study examined the experiences of bilingual/multilingual therapists working with bilingual/multilingual clients. Utilizing interviews with twelve bilingual/multilingual therapists who were linguistically diverse, this study analyzed the process of language switching in therapy, the effects of shared versus different languages on countertransference experiences, the interview subjects' conceptualizations of linguistic identity and how these identities have come to influence professional development, as well as the role that language plays in academic and training settings for mental health practitioners. Among the recommendations, the study proposes that academic programs should include discussions about psycholinguistic histories in the context of sound clinical 
interviewing and psychosocial assessments. Additionally, the study recommends that supervisory settings should include explorations of a supervisee's linguistic identity as it interplays with their professional identity.

\section{Relationship between Ethnic/Racial Identity Development Models, Culture, and Language}

When the multicultural movement evolved in the 1960s, the prominent idea was the conception of ethnic/racial identity models. These provided a framework to conceptualize how individuals from dominant and nondominant groups developed their identities and similarly, what human service providers needed to pay attention to in order to provide more efficient services with a higher degree of sensitivity. Figure 1 presents the predominant models and research studies that paved the way for the reconceptualization of race and ethnicity in the U.S.

Figure 1

Predominant models and research studies of ethnic/racial identity

\begin{tabular}{|l|c|}
\hline Black racial identity & $\begin{array}{c}\text { Psychological nigrescence (Cross, 1971); } \\
\text { Psychological nigrescence revised and expanded } \\
\text { model (Cross, 1995; Cross \& Vandiver, } \\
2001) ;\end{array}$ \\
& $\begin{array}{r}\text { Multidimensional model of Black identity (Sellers, } \\
\text { Shelton, Cooke, Chavous, Rowley, \& Smith, } \\
(1998) ; \text { Sellers, Smith, Shelton, Rowley, \& } \\
\text { Chavous (1998). }\end{array}$ \\
\hline White racial & $\begin{array}{c}\text { White racial consciousness model (LaFleur, Rowe, \& } 2002 ; \text { Rowe, 2006) } \\
\text { identity/consciousness }\end{array}$ \\
& White racial identity development (Helms, 1984) \\
\hline Ethnic identity & Ego and social identity (Erikson, 1968; Marcia, 1980; \\
& Tajfel, 1981) \\
\hline
\end{tabular}


According to Brown and Hewstone (2005), counselors can better serve the growing multiethnic population in the U.S. through immersion and interaction with different cultures and their representative languages. Cultural immersion promotes multicultural counseling development by expanding self-awareness, improving multicultural skills, and broadening multicultural understanding (DeRicco \& Sciarra, 2005). There is an inherent relationship between ethnic/racial development models, their cultures, and the languages represented by them. Language is another extension of culture and a critical dimension for the construct of identity (Celinska \& Swazo, 2016).

In summary, the provider's multilingual competence for effective counseling and psychological services to bi/multilingual clientele is an important element that has not been addressed in-depth with all its respective ramifications. Similarly, these dynamics reflect a language-based mismatch between the predominantly monolingual providers and the linguistically diverse clientele. Hence, further research is needed to understand the relationship between the level providers' language competence and their ability to provide professional services in the client's' native language (i.e., cultural-linguistic professional competence).

To address this gap in the existing literature, the current study was designed to address the following research questions: (1) what is the relationship between the providers' language competence and their cultural-linguistic professional competence? and (2) what are the relationships among different levels of the providers' language competence and their cultural-linguistic professional competence? In an attempt to answer these questions, the study provides valuable, research-based recommendations for incorporating languagebased training as an integral part of preparing professionals who work with linguistically diverse populations.

\section{Methods}

\section{Instrument, Measures and Procedure}

To address the study's research questions, a questionnaire entitled the Multilingual Competence in Counselor Education and Allied Disciplines (MCCEAD) was utilized. The MCCEAD was developed by the first author to measure the levels of language competence and cultural-linguistic professional competence. The participants were approached by the authors and/or trained graduate assistants and explained the purpose and procedures of the study. Those who opted to participate in the study signed a written consent and were subsequently given the MCCEAD questionnaire. All responses to the 
questionnaire items were anonymous. The above procedure was approved by the IRB committees at all higher education institutions involved in this study. Out of those approached, 95\% consented to participate and completed all items on the MCCEAD.

The items that were designed to measure the levels of Language Competence and Cultural-Linguistic Professional Competence are presented in Table 1.

Language Competence in this study is measured based on the participants' self-report (i.e., responses to the MCCEAD items) at the following three levels: (1) Bilingualism, (2) Academic-Based Second Language, and (3) CulturallyEmbedded Bi/Multilingualism. Bilingualism is indicated by the participant's endorsement of one of the specified degrees of bilingualism (Items 1-3 in Table $1)$.

Academic-Based Second Language is designated when the participant marks at least one year of instruction in second language at middle/high school and/or college (Items 4-5 in Table 1). Culturally-Embedded Bi/Multilingualism represents the social bi/multilingual interactions with others and media (e.g., music, TV, printed materials), the use of native language of the ancestors when visiting their homeland, and the readiness to emigrate to a foreign country based on the knowledge of this country's language and customs (Items 6-11 in Table 1). Cultural-Linguistic Professional Competence is measured as the total number of endorsements (i.e., "yes" answers) to items indicating comfort and competency to provide in more than one/native language professional services. For instance, individual and group counseling/therapy, rendering clinical diagnoses, and conducting professional workshops and trainings (Items 12-15 in Table 1).

\section{Participants}

A total of 483 participants were recruited and responded to the MCCEAD, 411 students and 72 licensed practicing professionals. The students included 111 undergraduates and 300 graduates who were enrolled in 3 universities in the U.S.A.: one large size state Midwest university $(\mathrm{n}=248)$, one small size private Midwest university $(\mathrm{n}=153)$ and one mid-size state historically Black Southern university $(\mathrm{n}=10)$. The practicing professionals (non-university students or staff) were recruited through professional development activities with the large size state Midwest university mentioned above $(\mathrm{n}=37)$ and a small private university in Central America $(n=35)$. The students and practicing professionals represented 4 related disciplines as follows: counseling $(n=193)$, psychology $(n=146)$, social 
work $(n=61)$, and family services $(n=83)$. Table 2 shows the distribution of the participants across the institutions and disciplines.

Data on ethnicity, age and gender was available for 481 out of 483 participants.

The participants represented various ethnicities as follows: $71.5 \%$ were Euro American ( $\mathrm{n}=344), 5.8 \%$ African American $(\mathrm{n}=28), 0.4 \%$ Native American $(n=2), 15 \%$ Hispanic/Latino $(n=73), 0.8 \%$ Middle Eastern $(n=4), 0.6 \%$ Pacific Islander $(n=3), 1.7 \%$ Asian $(n=8), 3.3 \%$ Biracial $(n=16)$, and $0.6 \%$ Other $(n=3)$. Among all participants, $84 \%$ were females $(n=408)$ and $16 \%$ were males $(n=75)$. The participants' age spanned from young to mature adults as follows: $79 \%$ were $20-31$ years old $(n=379), 15 \%$ were $32-45$ years old $(n=71)$ and $6 \%$ were 46 or more years old $(n=31)$. Table 3 shows the distribution of the participants' age and gender across the ethnicity groups.

\section{Results}

\section{Contribution of Language Competence to Cultural-Linguistic Professional Competence}

Cultural-Linguistic Professional Competence (dependent variable) is comprised of four items pertaining to the respondent's comfort and competency to provide professional services in more than one/native language. The internal consistency of this set of items was evaluated using Cronbach's alpha. The value of alpha coefficient of .937 indicates that the items comprising Cultural-Linguistic Professional Competence have high internal consistency, and, therefore, represent a closely related set of professional competencies.

To evaluate whether the levels of Language Competence, as a group of independent variables, reliably predict the dependent variable, Cultural-Linguistic Professional Competence, standard multiple regression was conducted. The value of $\mathrm{F}(4,421)$ is $174.84, \mathrm{p}=.000$ and indicates that Language Competence is a statistically significant and reliable predictor of Cultural-Linguistic Professional Competence. The overall strength of the prediction is measured by the following values: R of .790 and Adjusted R-Squared of .621. Based on the Adjusted RSquared, $62.1 \%$ of variance in the dependent variable can be predicted from the independent variables. 


\section{Unique Contribution of Each Level of Language Competence to Cultural- Linguistic Professional Competence}

The unique contributions of each level of Language Competence (independent variables) to Cultural-Linguistic Professional Competence (dependent variable) were evaluated using standardized regression coefficient (Beta), as shown in Table 4. Two out of three levels of Language Competence significantly influence Cultural-Linguistic Professional Competence by increasing its degree as follows: Bilingualism (Beta=.135, $t=22.25, p=.000)$ and CulturallyEmbedded Bi/Multilingualism (Beta=2.041, $t=4.10, p=.000)$. These results indicate that Bilingualism is a stronger predictor of Cultural-Linguistic Professional Competence as compared to Culturally-Embedded $\mathrm{Bi} /$ Multilingualism. Academic-Based Second Language is a non-significant contributing variable to the Cultural-Linguistic Professional Competence (Beta=.022, $t=.718, p=.473)$.

To further explore the relationships between Language Competence and Cultural-Linguistic Professional Competence, each level of Language Competence was correlated separately with Cultural-Linguistic Professional Competency. The values of Pearson product-moment correlation coefficients shown in Table 5 indicate that two levels of Language Competence, Bilingualism and Culturally-Embedded Bi/Multilingualism, correlate positively and significantly with Cultural-Linguistic Professional Competence. CulturallyEmbedded Bi/Multilingualism correlates stronger $(r=.703, p=.000)$ than Bilingualism $(r=.430, p=.000)$. Importantly, these two levels of Language Competence are significantly but very weakly correlated $(\mathrm{r}=.134, \mathrm{p}=.005$ see Table 3). In contrast, Academic-Based Second Language is not significantly correlated to Cultural-Linguistic Professional Competence ( $r=.091, p=.059)$.

\section{Discussion and Implications}

The study results indicate that language competence of counselors, psychologists, and human services providers is an important factor influencing their cultural-linguistic professional competence defined as the ability to provide professional services in more than one/native language. Specifically, the providers' language competence accounts for $62 \%$ of their confidence and comfort in providing in another (non-native) language professional services such as conducting individual and group counseling/therapy, rendering clinical diagnoses, and conducting professional workshops and trainings. Given the fact that cultural-linguistic professional competence is, to a large degree, rooted in the professionals' level of language competence, it is imperative to incorporate 
language-based training for providers involved in delivering counseling, psychological, and human services to linguistically diverse clientele.

The current results yield some guidance for the language-based professional training designed to facilitate application of the provider's bi/multilingual skills to professional diagnostic, therapeutic and psychoeducational practices. In order to increase cultural-linguistic professional competence necessary to provide culturally and linguistically sensitive services, professionals should achieve the level of language competence that allows culturally-embedded use of another (non-native) language. This assumption stems from the current results that point out that only bilingualism and culturallyembedded bi/multilingualism significantly and positively influence and are significantly correlated with cultural-linguistic professional competence. Of critical importance is the fact that although professional competence correlates significantly with the bilingual status, self-identification as a bilingual individual does not necessarily imply language-based competence in professional activities. Indeed, the culturally meaningful use of language is linked to the provider's cultural-linguistic professional competence stronger than his/her selfidentification as bilingual individual. In contrast, academic-based second language does not account for, and is not correlated with, cultural-linguistic professional competence. Learning a second language in an academic environment through foreign language instruction (school and/or college) does not correspond to developing language-based competence in professional practices.

The current study has several limitations that should be taken into account when considering its results and implications. First, the number and selection of the items on the Multilingual Competence in Counselor Education and Allied Disciplines (MCCEAD) might have impacted the magnitude and pattern of the results. Future research that expands and/or emends the current set of questionnaire items may provide additional insights in answering the study's research question pertaining the relationship between language competence and cultural-linguistic professional competence. By the same token, future research may strengthen our current understanding of this relationship by exploring the inter-correlations among the three levels of language competence conceptualized in the current study (i.e. Bilingualism, Academic-Based Second Language, and Culturally-Embedded Bi/Multilingualism).

Second, the current data collected through a self-report instrument (MCCEAD) may reflect the limitations of this approach to analyzing multicultural competency. For example, Constantine and Ladany (2000) indicated positive relationship between multicultural counseling competency inventories and a 
measure of social desirability attitudes. Further, even with social desirability taken into account, self-reports of multicultural counseling competence were found to be unrelated to the ability to conceptualize multicultural cases. Given these limitations, future research should utilize other data collection methods (e.g., direct observation of counselor-client interactions and/or client survey or interviews) in conjunction with self-report of competency to expand and/or verify the current results. Third, the current results describe a heterogenous sample of human service providers that represent different levels of experience, disciplines, ethnicity/race and personal backgrounds. By disaggregating data based on these participant variables, future research may shed light into their possible impact on the relationship between language competence and cultural-linguistic professional competence. An integration of quantitative and qualitative research methodologies appears to have a potential to provide distinctive yet complementary findings to expand and enhance the inquiry undertaken by the current study.

Despite the above limitations, the study's findings seem to support the expansion of existing models of multicultural curricula in counseling, psychology and human services to incorporate bi/multilingual training to increase the trainees' ability to address the needs of linguistically diverse clientele. To maximize the effectiveness of such bi/multilingual training, trainees should be actively engaged in activities that facilitate culturally-embedded use of another (non-native) language. For instance, a bi/multilingual training approach may be grounded in clinical experiences with non-native English speakers that emphasize professional practices such as interviewing, diagnostic assessment, and individual and group interventions. Within any professional bi/multilingual training, the second language learning process must be enhanced by experiencing the nuances and intricacies of the professional terminology in order to make it relevant to the profession and clientele (Swazo, 2013).

Counselor education and human service training programs should be at the vanguard of specialized training by adding multilingual competences and cultural exchanges as part of their curricula. Principles from the Erasmus Program (European Commission, 2016) utilized by the European Union can be easily incorporated and replicated in counselor education and human services training programs and set a new invigorating standard for excellence in education. On the other hand, since a full language immersion model is not always feasible, practical or available due to the limitations of multilingual faculty and/or limited multilingual populations in a respective area of the country, other alternatives can be explored as alternatives. As a replacement, programs can consider implementing "micro-practicum activities." Micro-practicum activities comprise 
short-term, highly focused field experiences guided by the program's select competency and/or standard. For example, micro-practicum activities can be completed as part of the multicultural counseling course in which students are assigned to complete 2-10 hours of work with multilingual clients by means of interpreters or by attempting to do counseling in the client's native language through direct supervision of a bilingual supervisor. This is a new approach or concept that is being formulated by the authors and it is not typically incorporated in programs from a curricular standpoint. Another alternative is to partner with the Study Abroad program and establish a conversational partner's relationship with the counseling program. These activities can be incorporated in a course or as an exit requirement to the program. The micro linguistic awareness activities serve as a base to expose English monolingual counselor education students to multilingual clients and to eventually raise their awareness pertaining language and culture.

\section{Conclusions}

Ethnic and racial identity models and their implications have dominated the counseling and psychology landscape since the 1960's. However, the dimension of language which is a critical element of the identity development for non-English speaking clients have been neglected in the literature. Similarly, the dynamics of English-speaking counselors and non-English speaking clients have not been studied to address the incremental growth of a non-English population in the U.S. which is vastly served by counselors who are English monolingual speakers.

Adaptability and innovation should be a trademark of counselor education and human service programs that modify and adjust training practices according to the needs of an increasingly multilingual and multicultural population. Being at the vanguard of specialization can set the new levels of multilingual/multicultural training standards in counselor education. The insentient omission of multilingualism as a critical multicultural variable in counseling processes, and the lack of its inclusion in counselor education curricula must be firmly addressed and reconsidered. 


\section{References}

American Psychological Association. (2002) Guidelines on multicultural education, training, research, practice, and organizational change for psychologists. Retrieved July 27, 2015 from http://www.apa.org/pi/oema/resources/policy/multicultural-guidelines.aspx

Association for Multicultural and Counseling Development. Multicultural Counseling Competencies Retrieved July 26, 2016 from http://www.counseling.org/resources/competencies/multcultural_competencies.pdf

Arredondo, P. M., Tovar-Blank, Z. G., \& Parham, T. A. (2008). Challenges and promises of becoming a culturally competent counselor in a sociopolitical era of change and empowerment. Journal of Counseling and Development, 86, 261-268. doi: 10.1002/j.1556-6678.2008.tb00508.x

Atkins, C. (2007, January/February). Enhancing job marketability: Bilingualism in California. The Therapist. San Diego, CA; Author. Retrieved October 13, 2015 from http://www.camft.org/AM/Template.cfm?Section=Home\&CONTENTID=10435\&TEMP LATE=/CM/ContentDisplay.cfm

Brooks, M., Kim, T., Moye, P., Oglesby, S., \& Hargett, B. (2015). Multicultural training in CCREP counselor education programs: A survey. International Journal of Social Science Studies, 3(6), 1-8. doi: 10.11114/ijsss.v3i6.985. Retrieved on July 28, 2016 from http://ijsss.redfame.com

Buckley, T. R. \& Foldy, E. G. (2010). A pedagogical model for increasing race-related multicultural counseling competency. The Counseling Psychologist, 38(5), 691-713. doi: $\underline{10.1177 / 0011000009360917}$

Brown, R., \& Hewstone, M. (2005). An integrative theory of intergroup contact. Advances in Experimental Social Psychology, 37, 255-343. doi: 10.1016/S0065-2601(05)37005-5

Celinska, D., \& Swazo, R. (2016). Multicultural Curriculum Designs in Counselor Education Programs: Enhancing Counselors-in-Training Openness to Diversity. The Journal of Counselor Preparation and Supervision, 8(3). doi: 10.7729/83.1124

Camarrota, S. A. (June, 2016). New data: Immigration surged in 2014 and 2015. Center for Immigration Studies. Retrieved July 27, 2016 from http://cis.org/New-Data$\underline{\text { Immigration-Surged-in-2014-and-2015 }}$

Celinska, D., \& Swazo, R. (2015). Intensive faculty-led international multiculturalcourses: Understanding the perceptions from students and improving the quality of course delivery by faculty. Journal of Education and Training Studies, 3(4), 127-136. doi: $\underline{10.11114 / \text { jets.v3i4.813 }}$

Constantine, M. G., \& Ladany, N. (2000). Self-report multicultural counseling competence scales: Their relation to social desirability attitudes and multicultural case

The Michigan Journal of Counseling: Theory, Research, and Practice Prepublication Release 
conceptualization ability. Journal of Counseling Psychology, Vol 47(2), 155-164. doi: $\underline{10.1037 / 0022-0167.47 .2 .155}$

Council for Accreditation of Counseling and Related Educational Programs 2009 Standards (2009). Retrieved July 27, 2016 from http://www.cacrep.org/doc/2009Standardswithcover.pdf

Council for Accreditation of Counseling and Related Educational Programs 2016 Standards (2016). Retrieved July 27, 2016 from http://www.cacrep.org/wpcontent/uploads/2012/10/2016-CACREP-Standards.pdf

Costa, B., \& Dewaele, J. (2014). Psychotherapy across languages: Beliefs, attitudes and practices of monolingual and multilingual therapists with their multilingual patients. Counselling and Psychotherapy Research, 14(3), 235-244. doi: 10.1080/14733145.2013.838338

Cross, W. E., Jr. (1971, July). The Negro-to-Black conversion experience: Toward a psychology. Philadelphia: Temple University Press.

Cross, W. E., Jr. (1991). Shades of Black: Diversity in African-American identity. Philadelphia: Temple University Press.

Cross, W. E., Jr. (1995). The psychology of nigrescence: Revising the Cross model. In J. G. Ponterotto, J. M. Casas, L. A. Suzuki, \& C. M. Alexander (Eds.), Handbook of multicultural counseling (pp. 93-122). Thousand Oaks, CA: Sage of Black liberation. Black World, 20, 13-27.

Cross, W. E., Jr., \& Vandiver, B. J. (2001). Nigrescence theory and measurement: Introducing the Cross Racial Identity Scale (CRIS). In J. G. Ponterotto, J. M. Casas, L. A. Suzuki, \& C. M. Alexander (Eds.), Handbook of multicultural counseling (2nd ed., pp. 371-393). Thousand Oaks, CA: Sage.

D'Andrea, M., \& Daniels, J. (1991). Exploring the different levels of multicultural counseling training in counselor education. Journal of Counseling and Development, 70, 78-85. doi: 10.1002/j.1556-6676.1991.tb01565.x

DeRicco, J. N., \& Sciarra, D. T. (2005). The immersion experience in multicultural counselor training: Confronting covert racism. Journal of Multicultural Counseling and Development, 33(1), 2-16. doi: 10.1002/j.2161-1912.2005.tb00001.x

Erikson, E. H. (1968). Identity: Youth and crisis. New York: Norton. European Commission (2016). Erasmus programme: EU Programme for education, training, youth, and sport. Retrieved July 27, 2016 from https://ec.europa.eu/programmes/erasmus-plus/about_en

Espín, O. M. (2013). "Making love in English": Language in psychotherapy with immigrant women. Woman and Therapy, 36(3-4), 198-218. doi: 10.1080/02703149.2013.797847

The Michigan Journal of Counseling: Theory, Research, and Practice Prepublication Release 
Helms, J. E. (1984). Toward a theoretical explanation of the effects of race on counseling: A Black and White model. The Counseling Psychologist, 12, 153-165. doi: $\underline{10.1177 / 0011000084124013}$

Hill, N. R. (2003). Promoting and celebrating multicultural competence in counselor trainees. Counselor Education and Supervision, 43, 39-51. doi: 10.1002/j.15566978.2003.tb01828.x

Hunter College (2016). Bilingual (Spanish/English) extension in pupil personnel services. Retrieved July 28, 2016 from http://catalog.hunter.cuny.edu/preview_program.php?catoid=3\&poid=345\&returnto=121

Hurley, E. J., Gerstein, L. H., \& Egisdóttir, S. (2013). Examining internationalization in U.S. Counseling psychology training programs. The Counseling Psychologist, 41(5), 724-749. $\underline{10.1177 / 0011000012436432}$

Ivers, N. N., Ivers, J. J., \& Duffey, S. T. (2013). Second language acquisition: Cultural, cognitive and clinical considerations for counseling practice. Journal of Creativity in Mental Health, 8(3), 219-234. doi: 10.1080/15401383.2013.821920

Jackson, B. (1976). Black identity development. In L. Gloubshick \& B. Persky (Eds.), Urban social and educational issues (pp. 158-164). Dubuque, IA: Kendall/Hunt.

Kokaliari, E., Catanzarite, G., \& Berzoff, J. (2013). It is called a mother tongue for a reason: A qualitative study of therapists' perspectives on bilingual psychotherapy-treatment implications. Smith College Studies in Social Work, 83(1), 97-118. doi: $\underline{10.1080 / 00377317.2013 .747396}$

LaFleur, N. K., Rowe, W., \& Leach, M. M. (2002). Reconceptualizing White racial consciousness. Journal of Multicultural Counseling and Development, 30, 148 -152. 10.1002/j.2161-1912.2002.tb00488.x

Marbley, A., Steele, J., \& McAuliffe, G. J. (2011). Teaching social and cultural issues in counseling. In G. J. McAuliffe \& K. P. Eriksen (Eds.). Handbook of counselor preparation. California, Thousand Oaks: Sage. doi: 10.4135/9781452230498.n12

Marcia, J. (1980). Identity in adolescence. In J. Adelson (Ed.), Handbook of adolescent psychology (pp. 159-187). New York: Wiley.

National Association of Manufacturers (2006). Improving workplace opportunities for Limited English-Speaking workers: An overview of practice in the manufacturing sector. Retrieved on July 25, 2016 from http://www.jff.org/sites/default/files/publications/ImprovWplaceELL.pdf

NYU-Steinhardt (2016). Counseling and guidance: School and bilingual school counseling, pre$K-12$. Retrieved July 28, 2016 from http://steinhardt.nyu.edu/appsych/ma/school_counseling 
Pedersen, P. (1988). A handbookfor developing multicultural awareness. Alexandria, VA: American Association of Counseling and Development.

Peters, M. L., Sawyer, C. B., \& Guzman, M. (2014). Supporting the development of Latino bilingual mental health professionals. Journal of Hispanic Higher Education, 13(1), 1531. doi: $10.1177 / 1538192713514611$

Ramos-Sánchez, L. (2009). Counselor bilingual ability, counselor ethnicity, acculturation, and Mexican Americans' perceived counselor credibility. Journal of Counseling and Development, 87(3), 311-318. doi: 10.1002/j.1556-6678.2009.tb00112.x

Rosenblum, S. M. (2011). The role of language in therapy: How bilingual/multilingual therapists experience their work with bilingual/multilingual clients. Smith ScholarWorks.

Rowe, W. (2006). White racial identity: Science, faith, and pseudoscience. Journal of Multicultural Counseling and Development, 34, 235-243. doi: 10.1002/j.21611912.2006.tb00042.x

Schoeman, R., Chiliza, B., Emsley, R., \& Southwood, F. (2008). Bilingualism and psychosis: A case report. Schizophrenia Research, 103(1-3), 333-335. doi: 10.1016/i.schres.2008.03.019

Sellers, R. M., Shelton, J. N., Cooke, D. Y., Chavous, T. M., Rowley, S. A., \& Smith, M. A. (1998). A multidimensional model of racial identity development: A reconceptualization of African American racial identity. In R. L. Jones (Ed.), African American identity development: Theory, research, and intervention (pp. 275-302). Hampton, VA: Cobb \& Henry.

Sellers, R. M., Smith, M. A., Shelton, J. N., Rowley, S. A. J., \& Chavous, T. M. (1998). Multidimensional model of racial identity: A reconceptualization of African American identity. Personality and Social Psychology Review, 2, 18 -39. doi: 10.1207/s15327957pspr0201_2

Shin, H. B., \& Kominski, R. A. (2010). Language use in the United States: 2007. Washington, D.C.; U.S. Department of Commerce. Retrieved July 29, 2015 from http://www.census.gov/prod/2010pubs/acs-12.pdf

Sue, D. W., Arredondo, P., \& McDavis, R. J. (1992). Multicultural counseling competencies and standards: A call to the profession. Journal of Counseling and Development, 70, 477-486. doi: 10.1002/j.1556-6676.1992.tb01642.x

Sue, D. W., Ivey, A. E., \& Pedersen, P. B. (1996). A theory of multicultural counseling and therapy. Pacific Grove, CA: Brooks/Cole.

Sue, D. W., \& Sue, D. (1999). Counseling the culturally different: Theory and practice ( ${ }^{\text {rd }}$ ed.). New Jersey: John Wiley \& Sons.

The Michigan Journal of Counseling: Theory, Research, and Practice Prepublication Release 
Swazo, R. (2013). The bilingual counselor's guide to Spanish: Basic vocabulary and interventions for the non-Spanish speaker. New York: Francis \& Taylor-Routledge. $10.4324 / 9780203136386$

Swazo, R. \& Celinska, D. (2014). Cutting edge practices to teach multicultural competencies in counseling, psychology, and education: Teaching abroad or on campus? Intercultultural Education, 25(2), 105-113. doi: 10.1080/14675986.2014.886821

Tajfel, H. (1981). Human groups and social categories. Cambridge, England: Cambridge University Press.

United States Census Bureau. (2012, December 12). U.S. Census Bureau projections show a slower growing, older, more diverse nation a half century from now (DHHS Publication No. CB12-243). Washington, D.C.: Author. Retrieved September 24, 2014 from http://www.census.gov/newsroom/releases/archives/population/cb12-243.htm

United States Census Bureau (2015). Comparison of migration data: 2013 American community survey and 2013 annual social and economic supplement of the current population survey. Working Paper Number SEHSD-WP2015-21.

United States Department of Education, National Center for Education Statistics (2015). The condition of education 2015, English Language Learners (NCES 2015-144).

University of LaVerne (2016). Spanish bilingual-bicultural concentration (SBBC). Retrieved July 28, 2016 from http://sites.laverne.edu/school-counseling/spanish-bilingualbicultural-certificate/

Vázquez, L. A., \& García-Vázquez, E. (2003). Teaching multicultural competence in the counseling curriculum. In D. B. Pope-Davis, H. L. K. Coleman, W. M. Liu, \& R. L. Toporek (Eds.), Handbook of multicultural competencies in counseling and psychology. Thousand Oaks, CA: Sage. 10.4135/9781452231693.n34

The Michigan Journal of Counseling: Theory, Research, and Practice Prepublication Release 